\title{
Novedades del género Tillandsia (Bromeliaceae, TILLANDSIOIDEAE) PARA URUGUAY
}

\author{
ANDRÉS J. ROSSADO ${ }^{*}$, SABINA DONADÍO ${ }^{2}$, PABLO BERAZATEGUI ${ }^{3} y$ \\ JOSÉ M. BONIFACINO ${ }^{1,4}$
}

\begin{abstract}
Summary: Novelties in the genus Tillandsia (Bromeliaceae, Tillandsioideae) for Uruguay. Tillandsia capillaris Ruiz \& Pav. (= T. capillaris f. hieronymi (Mez) L.B. Sm.) and T. loliacea Mart. ex Schult. are reported for the first time for the flora of Uruguay. Tillandsia capillaris is registered as an introduced and spontaneous species for Montevideo city, while $T$. Ioliacea is cited as native for northwestern Uruguay. Tillandsia tricholepis Baker is reported for the first time for natural environments in Uruguay, establishing its status as native. The recent finding of Tillandsia xiphioides Ker Gawl in Uruguay is reported after 73 years without being collected. We provide morphological descriptions, distribution and habitat data, phenology, conservation assessment, and images for each species treated.
\end{abstract}

Key words: Diaphoranthema, epiphyte, epilithic, flora of Uruguay.

Resumen: Se citan por primera vez para la flora de Uruguay a Tillandsia capillaris Ruiz \& Pav. (= T. capillaris f. hieronymi (Mez) L.B. Sm.) y T. Ioliacea Mart. ex Schult. f. Tillandsia capillaris es registrada como una especie introducida y espontánea para la ciudad de Montevideo, mientras que T. loliacea es citada como especie nativa del noroeste del país. Se presenta el primer registro de T. tricholepis Baker para ambientes naturales de Uruguay, confirmando el estatus de especie nativa. Se reporta el hallazgo reciente de $T$. xiphioides Ker Gawl luego de 73 años sin ser colectada en Uruguay. Este trabajo provee una descripción morfológica para cada especie, incluyendo información sobre su hábitat, distribución geográfica, fenología, estatus de conservación e imágenes.

Palabras clave: Diaphoranthema, epífita, epilítica, flora de Uruguay.

\section{INTRODUCCIÓN}

Tillandsia L. es el género con mayor número de especies y de más amplia distribución dentro de la familia Bromeliaceae. Este género comprende 739 especies (Gouda et al., continuamente actualizado) de plantas herbáceas de hábito epífito y/o epilítico, que se distribuyen desde el sur de Estados Unidos hasta el centro de Argentina y Chile (Smith \& Downs, 1977; Zizka et al., 2009; Barfuss et al., 2016; IBODA, continuamente actualizado). De acuerdo al estudio filogenético y la reciente revisión taxonómica de la subfamilia Tillandsioidea, Tillandsia ha sido clasificado en siete subgéneros y varios complejos de especies (Barfuss et al., 2016).
En Uruguay, Tillandsia es uno de los cinco géneros nativos de la familia Bromeliaceae y el único representante de la subfamilia Tillandsioideae. Este género se distribuye por todo el país y es uno de los componentes más importantes de la flora epifítica y epilítica de Uruguay, habitando todos los tipos de formaciones boscosas, así como también las principales formaciones rocosas. En la flora uruguaya Tillandsia está representado por 17 especies incluidas en cuatro subgéneros; Aerobia Mez, Anoplophytum (Beer) Baker, Diaphoranthema (Beer) Baker, y Phytarrhiza (Vis.) Baker. Del total de las especies dos son endémicas de Uruguay ( $T$. arequitae (André) André ex Mez y T. uruguayensis Rossado) y dos exóticas y subespontáneas en

\footnotetext{
${ }^{1}$ Laboratorio de Sistemática de Plantas Vasculares, Facultad de Ciencias, Universidad de la República, Montevideo, Uruguay.

${ }^{2}$ Instituto de Botánica Darwinion (CONICET-ANCEFN), San Isidro, Buenos Aires, Argentina.

${ }^{3}$ Asociación civil COENDU (Conservación de Especies Nativas de Uruguay), Montevideo, Uruguay.

${ }^{4}$ Laboratorio de Botánica, Facultad de Agronomía, Universidad de la República, Montevideo, Uruguay.

*arossado@fcien.edu.uy
} 
ambientes urbanos (T. virescens Ruiz \& Pav. (=T. cordobensis Hieron.) y T. capillaris Ruiz \& Pav.).

El objetivo del presente trabajo es dar a conocer las novedades respecto al género Tillandsia para Uruguay. En este sentido se reportan a Tillandsia capillaris (sensu Till, 1989a; Castello \& Galleto, 2013; Castello et al., 2016) y T. loliacea Mart. ex Schult. f. como nuevos registros para el país, se confirma el estatus de T. tricholepis Baker como especie nativa para Uruguay y se presenta el hallazgo reciente de T. xiphioides Ker Gawl. luego de 73 años de haber sido colectada por última vez en el país. Este trabajo incluye para cada una de estas cuatro especies una descripción morfológica, acompañada de imágenes y datos sobre hábitat, distribución geográfica, fenología, y estatus de conservación.

\section{Materiales y Métodos}

Los datos incluidos en este trabajo se obtuvieron a partir de la revisión de ejemplares de herbario (BA, BAB, CTES, HAS, HDCF, ICN, LP, MVFA, MVFQ, MVJB, MVM, PACA, PEL, SI; Thiers, continuamente actualizado), salidas de campo realizadas entre 2012 y 2014, y plantas mantenidas bajo cultivo.

Para la identificación de las especies se consultó bibliografía de referencia (Castellanos, 1945; Smith, 1972; Smith \& Downs, 1977; Castello \& Galetto, 2013; Donadío et al., 2015), protólogos y ejemplares tipo. Adicionalmente, se compararon las muestras procedentes de Uruguay con ejemplares de herbario procedentes de Argentina, Bolivia, Brasil y Paraguay. Los ejemplares colectados en este trabajo fueron depositados en MVFA, MVJB y MVM. La terminología morfológica utilizada para la descripción de las especies está basada en Smith \& Downs (1977), adaptado según Scharf \& Gouda (2008) y Barfuss et al. (2016).

La evaluación del estatus de conservación para cada especie sigue el sistema de clasificación propuesto por IUCN (2012), que clasifica a las especies en categorías de riesgo de extinción desde baja a elevada: Preocupación Menor, Casi Amenazada, Vulnerable, En Peligro, y En Peligro Crítico. Con el fin de poder asignarle a cada especie dichas categorías a nivel nacional, es que se aplicó el criterio de Rango geográfico a través de la evaluación del Área de ocupación
(“Area of occupancy”; AOO) (IUCN, 2012). Consideramos al AOO un buen estimador de la distribución real de las especies aquí tratadas ya que presentan distribución discontinua dentro del país. El AOO fue estimado mediante el software GeoCAT-Geospatial Conservation Assessment Tool (Bachman et al., 2011) utilizando un ancho de celda de $2 \mathrm{~km}$. Para estos análisis sólo se tomaron en cuenta los registros en ambientes naturales.

\section{Resultados}

Tillandsia capillaris Ruiz \& Pav., Fl. Peruv. 3: 42, pl. 271c. 1802. Tipo: PERÚ. Huánuco, s.d., Ruiz \& Pavón s.n. (Sintypus B-W06336-010!, BM000923922!, BM000923923!, BM000923925!, F0361001F!, MA810425!, MA810426!, MA810427!, MA810428!, P00753185!). Fig. 1A-C.

Plantas epífitas, caulescentes, muy ramificadas desde la base y formando matas globosas muy densas de hasta $11 \mathrm{~cm}$ de diámetro. Tallos de hasta $8 \mathrm{~cm}$ de largo pero comúnmente más cortos. Hojas dispuestas dísticamente, distribuidas a lo largo del tallo; vainas 5,5-10 × 2,7-4 $\mathrm{mm}$, cara abaxial lepidota en su mitad apical, cara adaxial mayormente glabra; láminas $8-17 \mathrm{~mm}$ de largo y $0,7-1,1 \mathrm{~mm}$ de diámetro, lineares, teretes, no acanaladas o si acanaladas por menos del $1 / 6$ basal, densamente lepidotas. Inflorescencias unifloras, excepcionalmente bifloras, sobresaliendo poco de la masa foliar; pedúnculos $13-70 \mathrm{~mm}$ de largo y 0,3-0,4 mm de diámetro, ebracteados o con una bráctea basal de aspecto foliáceo, glabros; brácteas florales envolviendo la flor, con pequeña porción laminar o elaminadas; vaina (3,2-) 3,8-5,4 × 2,8-4 $\mathrm{mm}$, anchamente elíptica a anchamente elípticoovada, adpresa, de verdosa con tintes vináceos a pajiza, glabra, ápice ampliamente redondeado; porción laminar de hasta $3 \mathrm{~mm}$ de largo pero generalmente menor a $2 \mathrm{~mm}$, lepidota. Flores 6-8,5 mm de largo, aroma suave; sépalos 4-6 $\times$ 1,3-1,7 mm, angostamente elípticos a angostamente oblongos, ecarenados, verdes en la base y vináceos hasta rojizos hacia el ápice o vináceos en toda su extensión, glabros, ápice obtuso a redondeado, sépalos adaxiales fusionados con el abaxial por 0,61,0 mm, adaxiales fusionados entre sí por 1,6-1,9 $\mathrm{mm}$ (menos de la mitad de su largo); pétalos 7,2-8,2 $\times$ 0,9-1,3 mm, ligulados, amarillos, la porción apical 

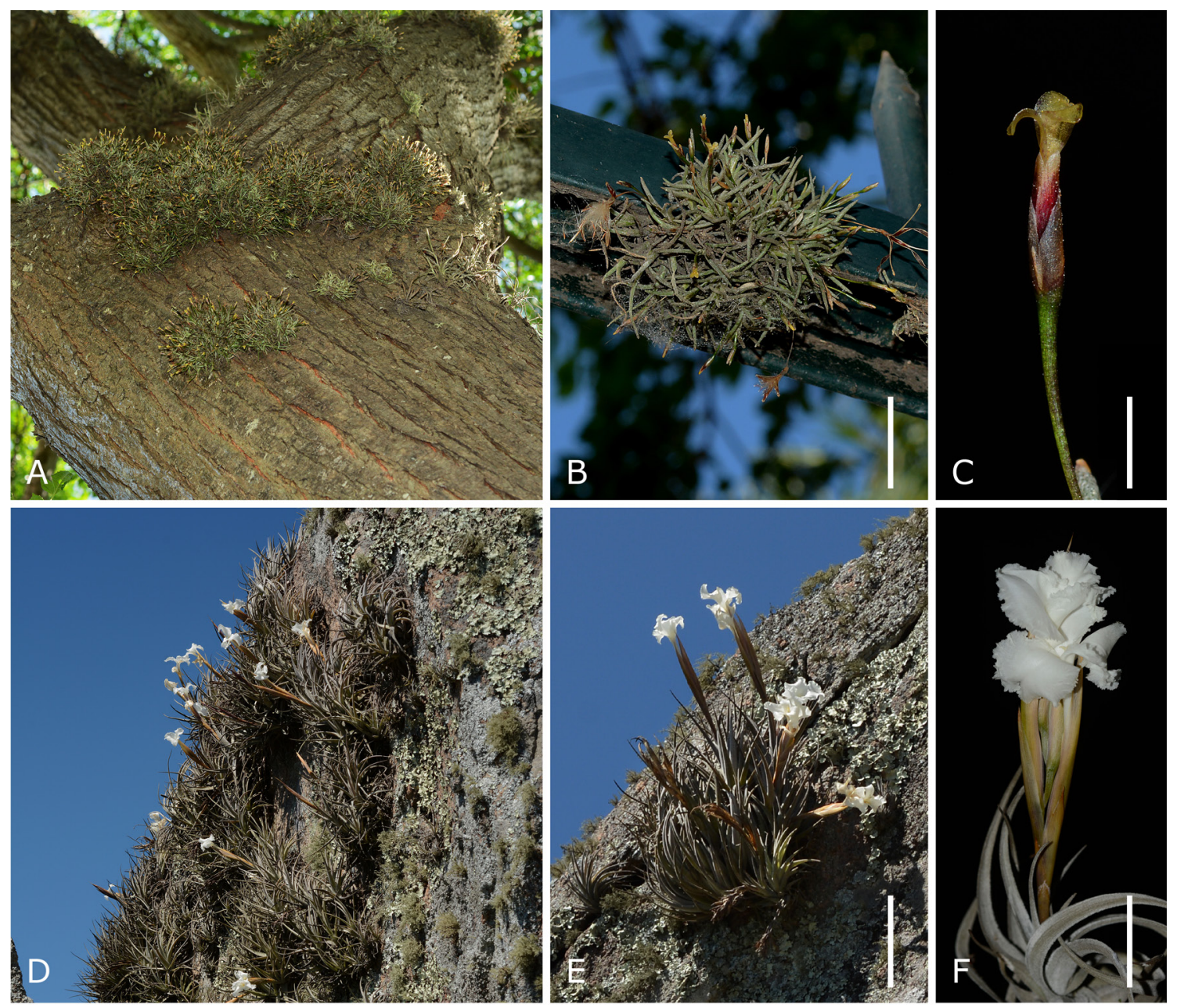

Fig. 1. A-C: Tillandsia capillaris. A: Ejemplares sobre arbolado público (ciudad de Montevideo, Uruguay). B: Individuo en floración (ciudad de Montevideo, Uruguay). C: Detalle de la inflorescencia. D-F: Tillandsia xiphioides. D: Población en ambiente natural (departamento de San José, Uruguay). E: Individuo en floración (departamento de San José, Uruguay). F: Detalle de la inflorescencia. Escalas= B: 2,5 cm; C: 3,5 mm; E: 7 cm; F: 2 cm. Imágenes A-F de Andrés Rossado.

con pequeñas manchas vináceas poco perceptibles, ápice redondeado, margen entero; estambres 3,2-3,6 $\mathrm{mm}$ de largo, profundamente inclusos, filamentos rectos; pistilo 1,8-2,3 $\mathrm{mm}$ de largo, no superando a los estambres. Cápsulas 12-22 × 0,7-1 mm, cilíndricas, ápice trunco a trunco-obtuso y cortamente apiculado.

Clasificación. Tillandsia capillaris pertenece al subgénero Diaphoranthema.

Distribución y hábitat. Tillandsia capillaris es una especie nativa de Perú, Bolivia, Chile y Argentina (con un registro para Ecuador; Till, 1989a; Krömer et al., 1999; Castello et al., 2016; IBODA, continuamente actualizado). En Uruguay se la encuentra como una especie exótica naturalizada para los departamentos de Colonia (un solo registro para el $\mathrm{A}^{\mathrm{o}}$ Riachuelo) y Montevideo (Fig. 2), donde se desarrolla en zonas urbanas de forma espontánea sobre diferentes sustratos como troncos y ramas del arbolado público, tendido eléctrico, paredes y rejas (Fig. 1A-B). Tillandsia capillaris suele cohabitar en un mismo soporte con T. aëranthos (Loisel.) L.B. Sm. y especies de aspecto general similar, como $T$. recurvata (L.) L. y T. virescens (= T. cordobensis), con las que se la puede confundir fácilmente. A su 


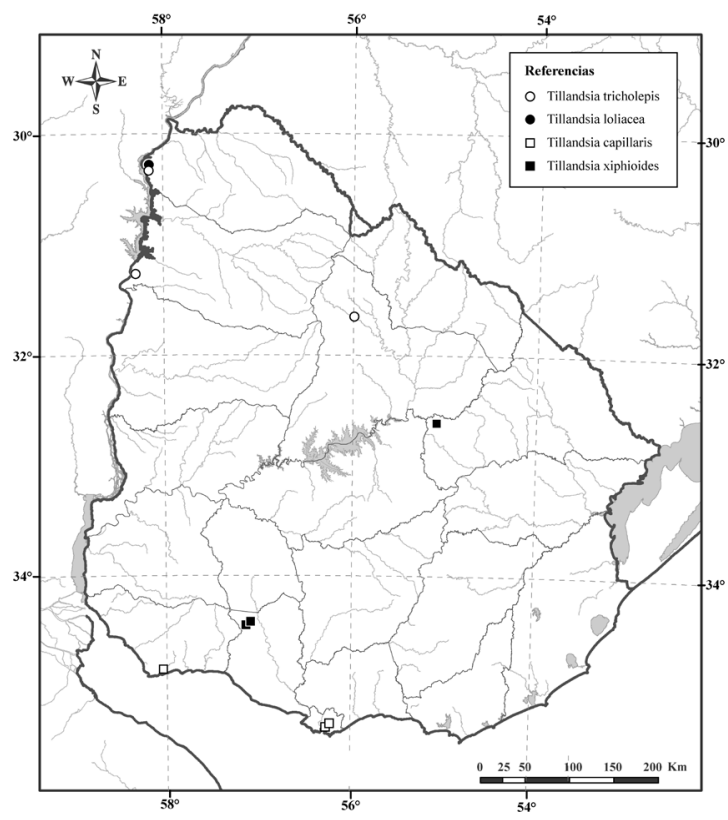

Fig. 2. Mapa de distribución de Tillandsia capillaris (cuadrados blancos), T. Ioliacea (círculo negro), T. tricholepis (círculos blancos) y T. xiphioides (cuadrados negros) en Uruguay. En el caso de $T$. tricholepis los puntos en los departamentos de Salto y Tacuarembó corresponden a poblaciones en zonas urbanas.

vez, ocasionalmente se pueden observar densas comunidades monoespecíficas de $T$. capillaris sobre el tronco o las ramas principales de los árboles de la ciudad (Fig. 1A).

Fenología. En Uruguay, Tillandsia capillaris florece en noviembre y diciembre, fructifica a partir de diciembre y se mantiene en fruto hasta octubre o noviembre del siguiente año.

Estatus de conservación. Dado que Tillandsia capillaris constituye una especie exótica para Uruguay, no aplica evaluar su estatus de conservación.

Observación I. En este trabajo seguimos la propuesta taxonómica de Till (1989a), Castello \& Galleto (2013), y Castello et al. (2016), en la cual el complejo Tillandsia capillaris quedó circunscripto, en base a evidencia morfológica y molecular, a dos especies: T. capillaris y $T$. virescens. La entidad presente en Uruguay, aquí tratada como $T$. capillaris, corresponde a lo que Smith \& Downs (1977) consideraron como T. capillaris f. hieronymi (Mez) L.B. Sm.

Observación II. Posiblemente Tillandsia capillaris ha pasado desapercibida para la flora de Montevideo (Smith, 1972; Lombardo, 1984; Brito \& Llano, 2008) debido a la gran similitud morfológica que posee con $T$. virescens, especie epífita y exótica que también se comporta como espontánea para la ciudad de Montevideo. Tillandsia capillaris se puede diferenciar claramente de $T$. virescens por la presencia de brácteas florales de vainas glabras (vs. densamente lepidotas) y sépalos adaxiales fusionados entre sí por menos de la mitad de su longitud (vs. más de $2 / 3$ de su longitud). Adicionalmente, dentro de la variación existente en Uruguay, $T$. capillaris se distingue de $T$. virescens por formar matas más compactas, poseer láminas más cortas, de 8-17 mm de largo (vs. 18-46 mm), sépalos de hasta $6 \mathrm{~mm}$ de largo (vs. mayores a 6 $\mathrm{mm}$ ), pétalos de 0,9-1,3 $\mathrm{mm}$ de ancho (vs. 1,4-2,5 $\mathrm{mm}$ ), y frutos de hasta $1 \mathrm{~mm}$ de ancho (vs. mayores a $1 \mathrm{~mm}$ ). Es importante destacar que $T$. virescens puede tener láminas y sépalos más cortos, y frutos más angostos en otras áreas de su distribución. A su vez, los pedúnculos de las plantas de $T$. virescens presentes en Uruguay son acrescentes, característica no observada en las plantas de $T$. capillaris presentes en el país. Por otro lado, en Uruguay, $T$. capillaris y $T$. virescens presentan diferencias en su fenología. Tillandsia capillaris florece de noviembre a diciembre mientras que $T$. virescens florece de agosto a octubre.

Tillandsia capillaris presenta cierta afinidad morfológica con T. recurvata, de la cual se diferencia claramente por formar matas más compactas, poseer láminas no acanaladas, o si acanaladas, por menos del $1 / 6$ basal (vs. acanaladas al menos en el $1 /{ }_{5}$ basal), pedúnculos ebracteados (si hay bráctea ésta es basal y de aspecto foliáceo) y glabros (vs. al menos con una bráctea peduncular en zona media y/o apical, y lepidotos o sublepidotos), y brácteas florales de vainas glabras (vs. lepidotas a densamente lepidotas).

Observación III. Smith (1972) y Brito \& Llano (2008) citan para Uruguay a Tillandsia capillaris (bajo el nombre de Tillandsia capillaris f. capillaris) en base al ejemplar Marchesi 1240 (MVM). Este ejemplar fue examinado y corresponde a $T$. virescens 


\section{A. J. Rossado et al. - Novedades de Tillandsia para Uruguay}

tal como había sido identificado por Marchesi (1965; bajo el nombre T. cordobensis). De esta manera se descarta el reporte de $T$. capillaris para Uruguay hasta el presente trabajo.

Observación IV. Consideramos a Tillandsia capillaris una especie exótica para Uruguay ya que la especie nunca fue registrada en ambientes naturales del país. Hasta el momento sólo se la ha encontrado creciendo en ambientes urbanos. Las poblaciones naturales de $T$. capillaris más cercanas a Uruguay se hallan en la zona sur de la provincia de Buenos Aires.

Material examinado. ARGENTINA. Prov. Córdoba: Dpto Colón, Ascochinga, 6-IV-1939, Giardelli 1191 (SI); Dpto. Santa María, Alta Gracia, I-1933, Fisher s.n. (BAA 7697); Dpto. Santa María, camino a dique de Los Molinos, 50 $\mathrm{km}$ al S de Córdoba, 30-II-1958, Boelcke 7625 (BAA). Prov. Santiago del Estero: Dpto Guasayán, Sierra de Guasayán, II-1945, Parodi 15040 (BAA). URUGUAY. Dpto. Colonia: Riachuelo, X-1949, Fabris \& Gebhard 67c (LP). Dpto. Montevideo: Ciudad de Montevideo, 15-XII-1972, Morey s.n. (MVFA 11894); Ciudad de Montevideo, Barrio Aires Puros, 22-III-2014, Rossado \& Haretche 352 (MVFA); Ciudad de Montevideo, Barrio Aires Puros, 16-XI-2014, Rossado 404 (MVFA); Ciudad de Montevideo, Barrio Brazo Oriental, 26-III-2017, Rossado 479 (MVJB).

Tillandsia loliacea Mart. ex Schult. f. in Roem. \& Schult., Syst. Veg. 7(2): 1204. 1830. Tipo: BRASIL. Bahía: "Habitat in rupibus M. Sancti", 1818, Martius s.n. (Holotypus M0111403!). Fig. 3A, B, D.

Plantas epífitas, muy cortamente caulescentes (de apariencia acaule), de tallo único o algo ramificadas desde la base constituyendo pequeñas matas. Hojas dispuestas espiraladamente, formando roseta basal; vainas 2-3,5 × 3-4,5 mm, glabras; láminas 11-30 × 2,5-7 mm, angostamente triangulares, densamente lepidotas, cara adaxial cóncava (lámina acanalada). Inflorescencias simples, conformadas por un racimo de flores dísticas; pedúnculos 16-70 $\mathrm{mm}$ de largo y 0,6$0,8 \mathrm{~mm}$ de diámetro, casi totalmente ocultos por las brácteas, lepidotos; brácteas pedunculares 5 a 6, envolventes, levemente más largas que los entrenudos, densamente lepidotas, las apicales elaminadas o con muy pequeña porción laminar a modo de acumen. Racimos 13-40 $\mathrm{mm}$ de largo (excluyendo pétalos), portando 3 a 7 flores sublaxamente dispuestas; raquis en su mayor parte expuesto, flexuoso, densamente lepidoto; brácteas florales 4-10 × 3-4,6 mm, envolviendo la flor, elíptico-oblongas, elaminadas o con muy pequeña porción laminar a modo de acumen, no imbricadas, desde apenas superando el entrenudo hasta 1,5 veces más largas que el entrenudo, verde grisáceas, densamente lepidotas, ápice agudo. Flores ca. $10 \mathrm{~mm}$ de largo, sin aroma; sépalos 5-8,2 × 1,5$1,9 \mathrm{~mm}$, angostamente elípticos, ecarenados, igualmente fusionados por ca. $1 \mathrm{~mm}$, verdes a vináceos, glabros a veces con tricomas hacia el ápice, ápice obtuso a redondeado; pétalos ca. $8 \times$ $1,5 \mathrm{~mm}$, ligulados, amarillos, ápice redondeado, margen entero; estambres ca. 3,5 $\mathrm{mm}$ de largo, profundamente inclusos, filamentos rectos; pistilo 2-2,8 $\mathrm{mm}$ de largo, muy incluso, no superando a los estambres. Cápsulas 22-34 × 1,2-1,8 mm, cilíndricas, ápice trunco y cortamente apiculado.

Clasificación. Tillandsia loliacea pertenece al subgénero Diaphoranthema.

Distribución y hábitat. Tillandsia loliacea se distribuye en Bolivia, Brasil, Paraguay, Argentina y Uruguay (Smith \& Downs, 1977; Till, 1989b; Krömer et al., 1999; Büneker et al., 2015; Flora do Brasil 2020, en construcción; IBODA, continuamente actualizado). En Uruguay, hasta el momento, sólo se ha registrado una única población para el norte del país, en el oeste del departamento de Artigas, en una zona cercana al Río Uruguay; límite con la provincia de Corrientes, Argentina (Fig. 2). Allí, T. loliacea crece exclusivamente como epífita, en un bosque de planicie, transicional entre el bosque ribereño y el bosque parque (bosque seco dominado por especies de Prosopis L.), sobre especies arbóreas como Coccoloba argentinensis Speg. y Ruprechtia laxiflora Meisn. En dicho bosque se desarrolla a media sombra, y cohabita con otras especies del género, como T. aëranthos, T. bandensis Baker, T. recurvata, y T. tricholepis.

A partir de los registros de herbario y los datos de distribución citados por Smith \& Downs (1977) y Till (1989b), se concluye que el norte de Uruguay y el sur de la provincia de Corrientes (Argentina) representan el límite sur de distribución de la especie. 

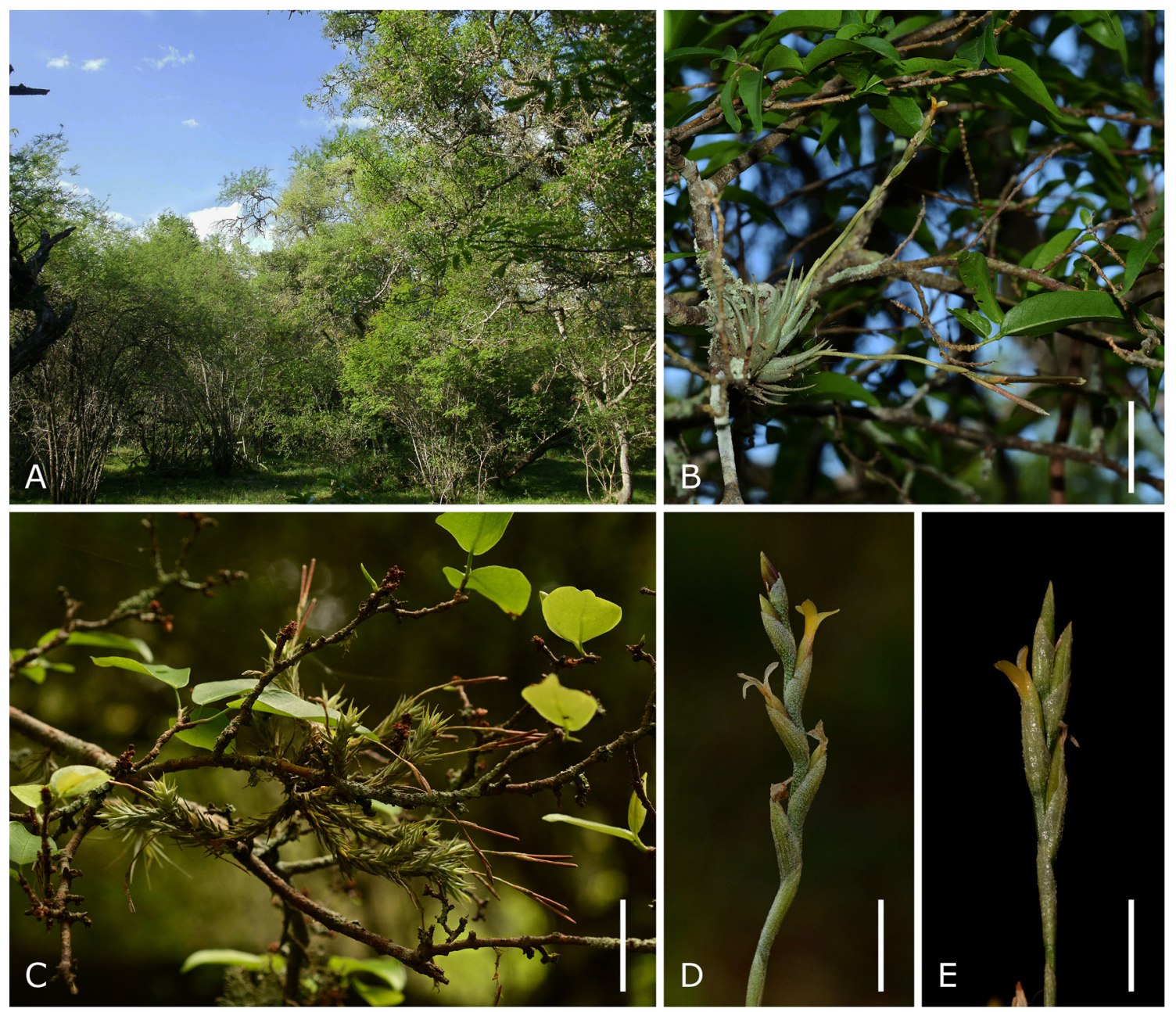

Fig. 3. Tillandsia loliacea y T. tricholepis. A: Vista general del hábitat en bosque de planicie (litoral del departamento de Artigas, Uruguay). B: Tillandsia loliacea, planta en floración y fructificación in situ (litoral del departamento de Artigas, Uruguay). C: Tillandsia tricholepis, planta con frutos in situ (litoral del departamento de Artigas, Uruguay). D: Tillandsia loliacea, detalle de la inflorescencia. E: Tillandsia tricholepis, detalle de la inflorescencia. Escalas= B: $2 \mathrm{~cm}$; C: $2,5 \mathrm{~cm}$; D: $1 \mathrm{~cm} ; \mathrm{E}: 0,5 \mathrm{~cm}$. Imagen A de Federico Haretche, Imágenes B-E de Andrés Rossado.

Fenología. No se tienen datos suficientes para determinar la fenología de Tillandsia loliacea para Uruguay. Ejemplares en flor fueron observados en setiembre y en fruto en marzo, julio y setiembre.

Estatus de conservación. Tillandsia loliacea fue categorizada en el análisis de AOO como en peligro crítico de extinción para Uruguay. Hasta el momento sólo se ha registrado una población de esta especie representada por menos de 10 individuos. Estos individuos se encuentran habitando un parche de bosque de escasa extensión (aprox. 2 ha) expuesto a fuertes presiones agrícolas. Dada esta situación, consideramos importante incluir a $T$. loliacea en el listado de especies prioritarias para la conservación de Uruguay. Cabe destacar que $T$. loliacea no se encuentra presente en ninguna de las áreas protegidas del "Sistema Nacional de Áreas Protegidas de Uruguay".

Observación I. Ejemplares juveniles o adultos poco desarrollados de Tillandsia loliacea pueden ser 


\section{A. J. Rossado et al. - Novedades de Tillandsia para Uruguay}

confundidos con plantas de T. tricholepis de escaso desarrollo. Estas especies se pueden diferenciar en estado juvenil por el aspecto de la lámina en su cara adaxial, siendo acanalada en $T$. loliacea y plana a convexa en $T$. tricholepis. En estado adulto, $T$. loliacea se diferencia claramente de T. tricholepis, por su hábito acaulescente (vs. caulescente), por poseer láminas más largas y anchas (al menos 11 $\mathrm{mm}$ de largo y 2,5 $\mathrm{mm}$ de ancho vs. menores a $9 \mathrm{~mm}$ de largo y $2 \mathrm{~mm}$ de ancho), y pedúnculos y raquis lepidotos a densamente lepidotos (vs. glabros).

Observación II. Castellanos (1945) incluye a Uruguay como parte de la distribución geográfica de Tillandsia loliacea. Sin embargo, en su trabajo no existen citas de ejemplares de herbario que avalen dicha afirmación.

Material examinado. ARGENTINA. Prov. Chaco: Dpto. General Güemes, entre Colonia Castelli y Fortín Lavalle, 18-I-1949, Ragonese \& Castiglioni 7111 (BAB). Prov. Corrientes: Dpto. Mercedes, Estancia Culantrillar, Laguna Trin, $75 \mathrm{~km}$ al $\mathrm{N}$ de Mercedes, 17-24-X-1975, Schinini et al. 11688 (CTES). Prov. Jujuy: Dpto. El Carmen, Pampa Blanca, 29-I-1937, Castellanos s.n. (BA 20257). BOLIVIA. Dpto. Tarija: Prov. O'Connor, Puerto Margarita, Río Pilcomayo, 3-V-1983, Krapovickas \& Schinini 39123 (CTES). BRASIL. Edo. Rio Grande do Sul: Mun. São Fransisco de Assis, Fazenda do Nei Paz, 16-XII-2013, Büneker \& Witeck 247 (HDCF). PARAGUAY. Dpto. Alto Paraguay: Parque Nacional Defensores del Chaco, 11-III-2005, Fortunato et al. 8719 (BAB). URUGUAY. Dpto. Artigas: Arrocera RIUSA- al sur del Arroyo Mandiyú, 28-IX-2014, Villagrán et al. s.n. (MVJB 30693).

Tillandsia tricholepis Baker, J. Bot. 16: 237. 1878. Tipo: BOLIVIA. La Paz: Larecaja, "Vicinüs Sorata; Poquerani, San Pedro, super frutices", 2500-2650 m, X-1858-IV-1959, Mandon 1179 p.p. (Sintypus BM000923944!, US00091125!, S-R-6158!, [G-DC] G-00493947!, K000321947!, P00438698!, P00438696!, P00438697!, MPU012478!, G00098166!, LE00006310!, W 18890262564!). Fig. 3A, C, E.

Plantas epífitas, caulescentes, ramificadas desde la base, con aspecto de musgo, formando matas subdensas. Tallos hasta $22 \mathrm{~cm}$ de largo, pero generalmente más cortos. Hojas dispuestas espiraladamente, distribuidas a lo largo del tallo; vainas 2-3,5 × (2,7-) 3,3-4,2 mm, glabras; láminas $4-9 \times 0,9-1,8 \mathrm{~mm}$, angostamente triangulares, densamente lepidotas, cara adaxial plano-convexa a convexa. Inflorescencias simples, conformadas por un racimo de flores dísticas; pedúnculos 10$40 \mathrm{~mm}$ de largo y ca. 0,5 $\mathrm{mm}$ de diámetro, en su mayor parte ocultos por las brácteas (parcialmente expuestos), glabros; brácteas pedunculares 2 (3), envolventes, aproximadamente del largo de los entrenudos, densamente lepidotas, las basales por lo general con pequeña porción laminar, las apicales elaminadas. Racimos 9-18 mm de largo (excluyendo pétalos), portando (1) 2 a 4 (5) flores densamente dispuestas, a veces con una flor estéril en el ápice; raquis visible, parcialmente oculto por brácteas y flores, levemente flexuoso, glabro; brácteas florales 3,8-8 × 3-4,2 mm, envolviendo la flor, ovadas a anchamente ovadas, elaminadas, no imbricadas, desde apenas superando el entrenudo hasta 2 veces más largas que el entrenudo, verdes a verde grisáceas, lepidotas a densamente lepidotas, ápice agudo. Flores 7-9 mm de largo, sin aroma; sépalos 5-7 × 1,4-2 mm, angostamente elípticos, ecarenados, igualmente fusionados por 0,9-2 $\mathrm{mm}$, verdes, lepidotos a sublepidotos en la mitad apical, ápice agudo a obtuso; pétalos 6,4-7,8 × 0,7$1,3 \mathrm{~mm}$, ligulados, amarillos, ápice redondeado, margen entero; estambres 3,2-4,3 $\mathrm{mm}$ de largo, profundamente inclusos, filamentos rectos; pistilo 1,8-2,9 $\mathrm{mm}$ de largo, incluso, no superando a los estambres. Cápsulas (11-) 14-20 × ca. 0,8-1,1 mm, cilíndricas, ápice trunco y cortamente apiculado.

Clasificación. Tillandsia tricholepis pertenece al subgénero Diaphoranthema.

Distribución y hábitat. Tillandsia tricholepis se distribuye en Bolivia, Paraguay, Brasil, Argentina y Uruguay (Smith \& Downs, 1977; Till, 1989b; Krömer et al., 1999; Flora do Brasil 2020, en construcción; IBODA, continuamente actualizado). En Argentina la especie posee amplia distribución y en cuanto a la cercanía con Uruguay, está presente en toda la provincia de Corrientes llegando hasta el norte de la provincia de Entre Ríos. En Uruguay, T. tricholepis hasta el momento había sido registrada sólo como espontánea en parques urbanos en las ciudades de Salto y de Tacuarembó. Este trabajo reporta el primer registro 
de la especie en ambientes naturales del país, en el oeste del departamento de Artigas, próximo al límite con Argentina (provincia de Corrientes) (Fig. 2). Allí se desarrolla de forma epífita en un bosque de planicie, transicional entre el bosque ribereño y el bosque parque, creciendo sobre troncos y ramas de variadas especies arbóreas como Coccoloba argentinensis, Ruprechtia laxiflora y Sebastiania sp., así como en la cactácea Harrisia bonplandii (Parm. ex Pfeiff.) Britton \& Rose. Esta población de $T$. tricholepis es de escasa extensión pero está representada por un número elevado de individuos, desde adultos formando matas grandes y de tallos largos, hasta juveniles y plántulas de escaso desarrollo.

En base al buen estado de conservación del bosque donde fue encontrada la especie y teniendo en cuenta la distribución de la especie en Argentina, consideramos a $T$. tricholepis como una especie nativa para Uruguay.

Fenología. En Uruguay, Tillandsia tricholepis florece desde diciembre a mediados de enero. La especie se encuentra en fruto desde enero hasta octubre-noviembre, meses donde ocurre la dehiscencia de las cápsulas.

Estatus de conservación. Tillandsia tricholepis fue categorizada en el análisis de AOO como en peligro crítico de extinción para Uruguay. Hasta el momento sólo se ha registrado una población natural de esta especie, habitando un parche de bosque de escasa extensión (aprox. 2 ha) ubicado en un área bajo fuerte presión de actividades agrícolas. Dada esta situación, consideramos que T. tricholepis debe ser tratada como una especie prioritaria para la conservación en Uruguay. Cabe destacar que $T$. tricholepis no se encuentra presente en ninguna de las áreas protegidas del "Sistema Nacional de Áreas Protegidas de Uruguay”.

Observación. Tillandsia tricholepis es la única especie de Tillandsia presente en Uruguay con aspecto de musgo o licofita de pequeño porte. Este carácter la hace fácilmente identificable de las restantes especies de Tillandsia presentes en el país. Sin embargo, ejemplares poco desarrollados de $T$. tricholepis pueden ser confundidos con ejemplares de pequeño porte de $T$. loliacea. Las diferencias entre ambas especies se especifican en la sección Observaciones de T. loliacea.
Material examinado. ARGENTINA. Prov. Corrientes: Dpto. Esquina, Ruta 27, $27 \mathrm{Km} \mathrm{S}$ de Esquina, 1-XII-1974, Krapovickas et al. 27065 (CTES); Dpto. Mercedes, Macrosistema Iberá, estancia Rincón del Diablo, 4-XII-1998, Schinini et al. 8267 (CTES). Prov. Entre Ríos: Dpto. La Paz, Estancia Pto. Márquez, 8-XII-1986, Guaglianone et al. 297 (SI); La Paz, I-1960, Burkart \& Bacigalupo 21511 (SI). Prov. Santiago del Estero: Dpto. Guasayán, Sierra del Guasayán, Quebrada de Conzo, 21-III-1989, Ulibarri 1648 (SI). BOLIVIA. Dpto Tarija: prov. Gran Chaco, $30 \mathrm{~km} \mathrm{~N} \mathrm{de} \mathrm{Tacuiba,}$ 7-IV-1977, Krapovickas \& Schinini 30975 (CTES). BRASIL. Edo. Paraná: Mun. Foz do Iguaçu, Cataratas del Iguazú, 14-I-1963, Marchesi 1042 (MVFA). Edo. Rio Grande do Sul: Mun. Santa Cruz do Sul, Trombudo, Morro dos Carrapatos, 6-XII1991, Waechter 2511 (PEL); Mun. São Leopoldo, 21-XI-1940, Leite 1896 (PACA). PARAGUAY. Dpto Cordillera: Cerro Tobatí, 19-XII-1987, Zardini \& Degen 4013 (CTES). URUGUAY. Dpto. Artigas: Establecimiento RIUSA, 16-III-2013, Villagrán \& Berazategui s.n. (MVM 23003); Paraje San Gregorio, Arrocera RIUSA, próximo a la costa del Río Uruguay, al S del Arroyo Mandiyú, 21-VII2013, Villagrán et al. s.n. (MVJB 30517). Dpto. Salto: Ciudad de Salto, Parque Solari, s.d, Del Puerto \& Ziliani s.n. (MVFA 17390); Parque Solari, 20-VI-2007, Brito \& Llano s.n. (MVFQ s.n.). Dpto. Tacuarembó: Plaza de la ciudad de Tacuarembó, 27-IX-2009, Brussa s.n. (MVJB 27154); Ciudad de Tacuarembó, Parque Rodó (planta bajo cultivo), 8-IX-2014, Rossado 363 (MVFA).

Tillandsia xiphioides Ker Gawl., Bot. Reg. 2: pl. 105. 1816. Tipo: Ilustración en el trabajo original (Holotypus pl. 105 en Ker Gawler (1816)). Fig. 1D-F.

Plantas epilíticas, raramente epífitas, desde acaulescentes a caulescentes, de tallo único o ramificadas desde la base, formando matas de hasta $60 \mathrm{~cm}$ de diámetro. Tallos generalmente cortos a veces hasta $25 \mathrm{~cm}$ de largo. Hojas dispuestas espiraladamente, agrupadas en el ápice del tallo; vainas 15-24 × 14-20 mm, cara abaxial densamente lepidota con zona basal glabra, cara adaxial glabra a excepción de zona apical densamente lepidota; láminas 85-180 × 10-20 mm, angostamente triangulares a muy angostamente 


\section{A. J. Rossado et al. - Novedades de Tillandsia para Uruguay}

triangulares, planas o a veces cóncavas (lámina acanalada), densamente lepidoto-tomentosas. Inflorescencias simples, conformadas por un racimo de flores dísticas; pedúnculos (35-) 55-140 (-165) $\mathrm{mm}$ de largo y ca. 2,5-3 mm de diámetro, totalmente ocultos por brácteas, glabros; brácteas pedunculares 5 a 9 , envolventes, densamente imbricadas, las basales de aspecto foliáceo y subglabras a lepidotas, las apicales elaminadas o muy cortamente laminadas y glabras o subglabras. Racimos 60-150 mm de largo (excluyendo pétalos), portando de 2 a 10 flores densamente dispuestas; raquis mayormente oculto por brácteas y flores, levemente flexuoso, glabro; brácteas florales (45-) 50-84 × 10-17 mm, envolviendo la flor, angostamente triangular-elípticas a angostamente ovado-elípticas, elaminadas, densamente imbricadas, de 4 a 6 veces más largas que el entrenudo, excediendo ampliamente en longitud a los sépalos, verde-amarillentas a moradas, glabras, ocasionalmente las basales con pocos tricomas dispersos, ápice agudo. Flores $65-100 \mathrm{~mm}$ de largo, aroma intenso y dulce; sépalos 32-48 $\times$ 5-12 mm, angostamente elípticos a angostamente elíptico-ovados, igualmente fusionados por $0,3-0,8$ $\mathrm{mm}$ (aparentando libres), glabros, ápice agudo a angostamente agudo, sépalo abaxial ecarenado, sépalos adaxiales carenados; pétalos $85-110 \mathrm{~mm}$ de largo, espatulados, blancos; limbo 17-30 mm de ancho, ápice agudo a redondeado, margen ondulado y fuertemente crenado; estambres 55-76 $\mathrm{mm}$ de largo, inclusos (llegando ca. la garganta de la corola), filamentos rectos; pistilo 64-96 mm de largo, exserto, superando a los estambres. Cápsulas 25-35 $\times$ 4-5 mm, angostamente elipsoides o angostamente elipsoide-ovoides, ápice agudo y cortamente apiculado.

Clasificación. Tillandsia xiphioides pertenece al subgénero Aerobia.

Distribución y hábitat. Tillandsia xiphioides se distribuye en Bolivia, Brasil, Argentina y Uruguay (Smith \& Downs, 1977; Krömer et al., 1999; Flora do Brasil 2020, en construcción; IBODA, continuamente actualizado). En Uruguay $T$. xiphioides es una especie de distribución muy restringida que se encuentra mayormente como epilítica, formando matas grises, muy ramificadas y densas, o inclusive plantas de tallo único, que crecen sobre paredones rocosos o bloques de roca expuestos a pleno sol. Generalmente forma comunidades monoespecíficas, aunque es común que crezca junto a especies de cactáceas o incluso junto a $T$. aëranthos. A su vez, esporádicamente se encuentran ejemplares epífitos sobre árboles próximos a las rocas donde la especie es más abundante.

Hasta el presente en Uruguay sólo se han encontrado dos poblaciones de Tillandsia xiphioides distantes entre sí (aproximadamente $240 \mathrm{~km}$ ), en los departamentos de Cerro Largo y San José (Fig. 2). Cabe destacar que no se han registrado poblaciones cercanas a las de Uruguay ni en Brasil, ni en Argentina. Las poblaciones más cercanas a las presentes en el país se encuentran en la provincia de Córdoba (Argentina).

Fenología. Tillandsia xiphioides florece en primavera, principalmente desde mediados de octubre hasta mediados de noviembre. Las plantas fructifican mayormente a partir de noviembre.

Estatus de conservación. Tillandsia xiphioides fue categorizada en el análisis de AOO como en peligro de extinción para Uruguay. Esta especie posee una alta probabilidad de desaparecer de los ambientes naturales del país si no se toman las medidas adecuadas de protección. Esto se debe no sólo a la distribución restringida de la especie dentro de Uruguay (dos localidades) sino también a la fuerte presión de colecta que sufre por parte de los coleccionistas, debido a su alto valor como planta ornamental.

Tillandsia xiphioides está incluida en el listado de las especies prioritarias para la conservación en Uruguay (Marchesi et al., 2013) bajo los criterios de "Especies de distribución restringida en Uruguay" y "Especies que han sufrido una disminución apreciable en su tamaño poblacional, por acciones humanas". Cabe destacar que esta especie no se encuentra presente en ninguna de las áreas protegidas del "Sistema Nacional de Áreas Protegidas de Uruguay".

Observación I. Tillandsia xiphioides fue colectada por última vez para Uruguay por Chebataroff en 1939 (Chebataroff s.n., MVM 11129) en la Sierra de Mahoma (departamento de San José), única localidad donde, hasta el momento, la especie había sido registrada para el país. Tillandsia xiphioides fue considerada extinta por Brito \& Llano (2008) para 
la Sierra de Mahoma luego de haber explorado sin éxito el área en diferentes épocas del año. En exploraciones realizadas entre 2012 y 2014 encontramos a $T$. xiphioides no sólo para el departamento de San José sino también para el departamento de Cerro Largo, confirmando de este modo la presencia de la especie para el país.

De todas maneras, cabe destacar que Brito \& Llano (2008) citan a T. xiphioides subsp. xiphioides y $T$. xiphioides var. minor L. Hrom. para el departamento de Tacuarembó (Uruguay). Luego de haber estudiado detalladamente la morfología de las entidades citadas en dicho trabajo, llegamos a la conclusión de que las mismas no corresponden a la especie T. xiphioides sino que se trata de la especie recientemente descripta: T. uruguayensis (Rossado et al., 2018). Tillandsia xiphioides se diferencia fácilmente de T. uruguayensis por presentar flores más grandes, de aroma intenso (vs. sin aroma), sépalos mayores o iguales a $32 \mathrm{~mm}$ de largo (vs. menores a $30 \mathrm{~mm}$ ), y pétalos mayores o iguales a $85 \mathrm{~mm}$ de largo (vs. menores a $60 \mathrm{~mm}$ ), de limbo igual o mayor a $17 \mathrm{~mm}$ de ancho (vs. menor a $11 \mathrm{~mm}$ ) y fuertemente crenado (vs. suavemente crenado hasta entero).

Observación II. Dentro de las especies de Tillandsia presentes en Uruguay, T. arequitae es la que más se asemeja a T. xiphioides tanto a nivel vegetativo como reproductivo. Tillandsia xiphioides se diferencia de $T$. arequitae por la presencia de brácteas florales basales de 45-84 mm de longitud (vs. 24,5-39 (-44) mm), sépalos mayores o iguales a $32 \mathrm{~mm}$ de largo (vs. iguales o menores a $30 \mathrm{~mm}$ ), pétalos mayores o iguales a 85 $\mathrm{mm}$ de largo (vs. menores a $70 \mathrm{~mm}$ ) y limbo del pétalo igual o mayor a $17 \mathrm{~mm}$ de ancho (vs. igual o menor a $11 \mathrm{~mm}$ ), entre otras características. Es de notar que, aunque $T$. arequitae y $T$. xiphioides habitan ambientes similares, hasta el momento no se las ha encontrado cohabitando.

Observación III. Los frutos de Tillandsia xiphioides suelen pasar muy desapercibidos debido a que se encuentran totalmente ocultos por las brácteas florales que envuelven y superan ampliamente en longitud al fruto.

Material examinado. ARGENTINA. Prov. Catamarca: Dpto. Valle Viejo, El Portezuelo, 9-XII-1972, Ulibarri 242 (SI). Prov. Córdoba:
Dpto. Cruz del Eje, Serrezuela, 8-XII-1942, Bartlett 19223 (SI). Prov. Mendoza: Dpto. San Rafael, entre Punta de Agua y La Pintada, XII-1933, Ragonese s.n. (BA 12545). Prov. San Juan: Dpto. Valle Fértil, Ischigualasto, 19-XI-1982, Kiesling \& Saenz 4280 (SI). Prov. San Luis: Dpto Belgrano, Villa General Roca, 19-XI-1926, Castellanos s.n. (BA 26/2052). Prov. Salta: Dpto. Cafayate, Valle del Cafayate, 7-I1914, Rodríguez 1252 (LP). Prov. Tucumán: Dpto. Trancas, entre Tapias y Vipos, 28-XI-1920, Venturi 1316 (LP). URUGUAY. Dpto. Cerro Largo: Cerca de Paso Pereira, 2-XI-2014, Rossado et al. 384 (MVFA). Dpto. San José: Sierra de Mahoma, XII1894, señorita de Larriera s.n. (Herb. Osten 3122 , MVM s.n.); Sierra de Mahoma, 1939, Chebataroff s.n. (MVM 11129); Sierra de Mahoma, 17-XI-2012, Rossado et al. 24 (MVJB); Sierra de Mahoma, 22X-2014, Rossado 377 (MVFA).

\section{Agradecimientos}

Expresamos nuestro agradecimiento a Federico Haretche quien aportó datos acerca de la presencia de Tillandsia capillaris para Montevideo, a Carlos Brussa por presentar y facilitar datos de presencia de T. xiphioides en Uruguay, y especialmente a Eduardo Villagrán quien participó en el nuevo registro a campo de T. loliacea y T. tricholepis. A su vez, agradecemos a los revisores del artículo por sus aportes y a todos los curadores de los herbarios visitados (BA, BAB, CTES, HAS, HDCF, ICN, LP, MVFA, MVJB. MVM, PACA, PEL, SI) por su predisposición y amabilidad a la hora de coordinar y efectuar las visitas.

\section{Bibliografía}

BARFUSS, M. H. J., W. TILL, E. M. C. LEME, J. P. PINZÓN, J. M. MANZANARES, H. HALBRITTER, R. SAMUEL \& G. K. BROWN. 2016. Taxonomic revision of Bromeliaceae subfam. Tillandsioideae based on a multi-locus DNA sequence phylogeny and morphology. Phytotaxa 279: 1-97.

BACHMAN, S., J. MOAT, A. W. HILL, J. DE LA TORRE \& B. SCOTT. 2011. Supporting Red List threat assessments with GeoCAT: geospatial conservation assessment tool. (Version BETA). In: SMITH V. \& L. PENEV (eds) e-Infrastructures for data publishing in biodiversity science. ZooKeys 150: 117-126. Disponible en: <http://geocat.kew. org/>. [Acceso 15 marzo 2017]. 


\section{A. J. Rossado et al. - Novedades de Tillandsia para Uruguay}

BRITO, A.H. \& L. LLANO. 2008. Bromelias del Uruguay. Ed. Linardi y Risso, Montevideo.

BÜNEKER, H. M., R.C. PONTES \& L. WITECK. 2015. Novos registros em Tillandsia L. (Bromeliaceae, Tillandsioideae) para o Rio Grande do Sul, Brasil. Rodriguésia 66: 493-498.

CASTELLANOS, A. 1945. Bromeliaceae. In: DESCOLE H. R. (Ed) Genera et species plantarum Argentinarum 3: 105-378. Guillermo Kraft Ltda., Buenos Aires.

CASTELlO, L. V. \& L. GALETTO. 2013. How many taxa can be recognized within the complex Tillandsia capillaris (Bromeliaceae, Tillandsioideae)? Analysis of the available classifications using a multivariate approach. PhytoKeys 23: 25- 39.

CASTEllO, L.V., M. H. J. BARFUSS, W. TILL, L. GALETTO \&. J.O. CHIAPELLA. 2016. Disentangling the Tillandsia capillaris complex: phylogenetic relationships and taxon boundaries in Andean populations. Bot. J. Linn. Soc. 181: 391414.

DONADÍO, S., R. POZNER, \& L. M. GIUSSANI. 2015. Phylogenetic relationships within Tillandsia subgenus Diaphoranthema (Bromeliaceae, Tillandsioideae) based on a comprehensive morphological dataset. Pl. Syst. Evol. 301: 387-410.

FLORA DO BRASIL 2020. En construcción. Jardim Botânico do Rio de Janeiro [online]. Disponible en: http://floradobrasil.jbrj.gov.br/reflora/floradobrasil/ FB6362 [Acceso: 15 febrero 2018].

GOUDA, E. J., D. BUTCHER \& C. S. GOUDA. Continuamente actualizado. Encyclopaedia of Bromeliads, version 3. University Botanic Gardens, Utrecht. Disponible en: http://encyclopedia.florapix. $\mathrm{nl} /$ [Acceso: 25 julio 2018].

IBODA. Continuamente actualizado. Base de datos. Flora del Cono Sur. Instituto de Botánica Darwinion. Buenos Aires, Argentina [online]. Disponible en: http://www2.darwin.edu.ar/ [Acceso: 15 febrero 2018].

IUCN. 2012. IUCN Red List Categories and Criteria, Version 3.1. 2nd ed. IUCN, Gland, Switzerland and Cambridge.

KER GAWLER, J. B. 1816. The Botanical Register 2. James Ridgway, Piccadilly, London.

KRÖMER, T., M. KESSLER, B. K. HOLST, H. E. LUTHER, E. J. GOUDA, P. L. IBISCH, W. TILL \& R. VÁSQUEZ. 1999. Checklist of Bolivian Bromeliaceae with notes on species distribution and levels of endemism. Selbyana 20: 201-223.
LOMBARDO, A. 1984. Flora Montevidensis. Tomo 3, Monocotiledóneas. Intendencia Municipal de Montevideo, Montevideo.

MARCHESI, E., E. ALONSO PAZ, L. DELFINO, M. GARCÍA, F. HARETCHE \& C. BRUSSA. 2013. Plantas Vasculares. In: SOUTULLO, A., C. CLAVIJO \& J. A. MARTÍNEZ-LANFRANCO (eds.) Especies prioritarias para la conservación en Uruguay. Vertebrados, moluscos continentales $y$ plantas vasculares, pp. 27-71. SNAP/DINAMA/ MVOTMA y DICYT/MEC, Montevideo.

MARCHESI, E. H. 1965. Plantas nuevas o poco conocidas de la flora Uruguaya I. Comun. Bot. Mus. Hist. Nat. Montevideo 4:1-3.

ROSSADO, A. J., S. DONADIO \& J. M. BONIFACINO. 2018. Tillandsia uruguayensis (Tillandsioideae, Bromeliaceae), a new epilithic species from Uruguay. Phytotaxa 345: 133-142.

SCHARF, U. \& E. J. GOUDA. 2008. Bringing Bromeliaceae back to homeland Botany. $J$. Bromeliad Soc. 58: 123-129.

SMITH, L. B. 1972. Flora del Uruguay IV. Bromeliaceae. Comun. Bot. Mus. Hist. Nat. Montevideo 4: 1-31.

SMITH, L. B. \& R. J. DOWNS. 1977. Tillandsioideae (Bromeliaceae). Flora Neotrop. 14: 659-1492.

THIERS, B. Continuamente actualizado. Index Herbariorum: A global directory of public herbaria and associated staff. New York Botanical Garden's Virtual Herbarium [online]. Disponible en: http:// sweetgum.nybg.org/ih//. [Acceso: 20 diciembre 2017].

TILL, W. 1989a. Die Untergattung Diaphoranthema (Beer) C. Koch von Tillandsia Linnaeus. 1, Das Tillandsia capillaris Aggregat. Die Bromelie 2: 3134.

TILL, W. 1989b. Die Untergattung Diaphoranthema (Beer) C. Koch von Tillandsia Linnaeus. 2, Das Tillandsia loliacea Aggregat. Die Bromelie 3:55-59.

ZIZKA, G., M. SCHMIDT, K. SCHULTE, P. NOVOA, R. PINTO \& K. KÖNIG. 2009. Chilean Bromeliaceae: diversity, distribution and evaluation of conservation status. Biodivers. Conserv. 18: 2449-2471.

Recibido el 8 de mayo de 2018, aceptado el 28 de agosto de 2018. Editora: Carolina I. Calviño. 
